\title{
An economic evaluation of voriconazole versus amphotericin B for the treatment of invasive aspergillosis in Canada
}

\author{
Coleman Rotstein MD FRCPC ${ }^{1}$, Michel Laverdière $\mathrm{MD}^{2}$, Anne Marciniak MD ${ }^{3}$, Farzad Ali BPharm MSc ${ }^{4}$
}

C Rotstein, M Laverdière, A Marciniak, F Ali. An economic evaluation of voriconazole versus amphotericin B for the treatment of invasive aspergillosis in Canada. Can J Infect Dis Med Microbiol 2004;15(5):277-284.

BACKGROUND: Invasive aspergillosis (IA) is a serious fungal infection that affects immunocompromised patients. The Global Comparative Aspergillosis study demonstrated that voriconazole, a new broad-spectrum triazole, had better responses and improved survival compared with conventional amphotericin B deoxycholate $(\mathrm{CAB})$ and other licensed antifungal therapy (OLAT) for the treatment of definite or probable aspergillosis.

OBJECTIVES: To compare costs and outcomes of voriconazole and $\mathrm{CAB}$ for the treatment of definite or probable aspergillosis in Canada. METHODS: A cost-consequence decision tree model was designed to reflect the treatment pathways used in clinical practice when using voriconazole or CAB as primary therapy for IA. Therapy included initial treatment with either voriconazole or $\mathrm{CAB}$ and then switched to an OLAT in the event of an inadequate response, severe toxicity or intolerance. The principal data source used was the Global Comparative Aspergillosis study.

RESULTS: The total cost of voriconazole when compared with $\mathrm{CAB}$ as initial therapy for IA was $\$ 38,319$ versus $\$ 42,495$ per patient, respectively, representing a $9.8 \%$ cost reduction for each patient treated with voriconazole. The higher mean cost in the CAB arm was primarily due to the high proportion of patients $(73.7 \%)$ who were switched to an OLAT due to severe side effects or an inadequate response. Treating with voriconazole was a dominant strategy. The number of patients that had to be treated with voriconazole instead of $\mathrm{CAB}$ to save one additional life was eight.

CONCLUSIONS: Voriconazole as primary treatment for IA increased the chances of successful treatment, improved survival and may represent a potential cost saving strategy in Canada.

\section{Une évaluation économique du voriconazole par rapport à l'amphotéricine $B$ pour le traite- ment de l'aspergillose envahissante au Canada}

HISTORIQUE : L'aspergillose envahissante (AE) est une grave infection à champignon dont souffrent les patients immunocompromis. Létude comparative mondiale de l'aspergillose a démontré que le voriconazole, un nouveau triazole à large spectre, assurait de meilleures réponses et une meilleure survie que l'amphotéricine $\mathrm{B}$ déoxycholate traditionnel (ABDT) et d'autres traitements antifongiques (ATA) homologués pour le traitement de l'aspergillose définie ou probable.

OBJECTIFS : Comparer les coûts et les issues du voriconazole et de l'ABDT pour le traitement d'une aspergillose définie ou probable au Canada.

MÉTHODOLOGIE : Un modèle d'arbre décisionnel tenant compte des coûts a été conçu pour refléter les voies thérapeutiques utilisées en pratique clinique au moment d'utiliser le voriconazole ou l'ABDT comme traitement primaire de l'AE. La thérapie incluait un traitement initial au voriconazole ou à l'ABDT, suivi d'un ATA en cas de réponse déficiente, de grave toxicité ou d'intolérance. La principale source de données utilisée était l'étude comparative mondiale de l'aspergillose.

RÉSULTATS : Le coût total du voriconazole comparativement à l'ABDT comme traitement initial de l'AE s'élevait à 38319 \$ par rapport à $42495 \$$ par patient, respectivement, représentant une réduction de 9,8 \% du coût par patient traité au voriconazole. Le coût moyen plus élevé de l'ABDT était principalement causé par la forte proportion de patients $(73,7 \%)$ qui ont dû passer à un ATA en raison de graves effets secondaires ou de réponse déficiente. Le traitement au voriconazole était une stratégie dominante. Huit patients ont dû subir un traitement au voriconazole plutôt qu'à l'ABDT pour sauver une vie supplémentaire.

CONCLUSIONS : Le voriconazole comme traitement primaire de l'AE accrôt les possibilités de réussite du traitement, améliore la survie et peut représenter une stratégie potentielle d'économies pour le Canada.

Key Words: Amphotericin B; Aspergillosis; Costs; Cost-effectiveness; Voriconazole

Invasive aspergillosis (IA) is a serious fungal infection that affects immunocompromised patients, particularly those with hematological malignancies and those who have undergone hematopoietic stem cell or solid organ transplantation (1). Studies in the United States (US) indicate that the incidence of serious fungal infections has increased significantly in hospitalized patients over the past 20 years (2,3). A 4.5-fold annual increase was estimated for IA incidence between 1996 and 1999 (3). In Canada, the annual incidence of invasive fungal infection was estimated to be between 3.54 and 6.64

${ }^{1}$ Division of Infectious Diseases, Department of Internal Medicine, McMaster University, Hamilton, Ontario; ${ }^{2}$ Department of Microbiology-Infectious Diseases, Hôpital Maisonneuve-Rosemont, Montréal, Quebec; ${ }^{3}$ Pfizer Ltd, Sandwich, United Kingdom; ${ }^{4}$ Pfizer Canada, Kirkland, Quebec Correspondence and reprints: Dr Coleman Rotstein, Henderson Site, Hamilton Health Sciences, 711 Concession Street, Hamilton, Ontario

L8V 1C3. Telephone 905-574-3301, fax 905-389-0108, e-mail crotstei@mcmaster.ca

Received for publication April 5, 2004. Accepted July 23, 2004 
cases per 100,000 from 1992 to 1994 (4). Although IA cases comprise $5 \%$ to $10 \%$ of all invasive fungal infections, they account for the greatest mortality (4).

IA progresses quickly in severely immunocompromised patients and, despite treatment, the mortality rate ranges from $57 \%$ to $100 \%$ (5). The current gold standard treatment for IA is conventional amphotericin $\mathrm{B}$ deoxycholate (CAB) (6). However, response rates to therapy with $\mathrm{CAB}$ vary between $14 \%$ and $83 \%$, depending on the site of infection and the nature of the underlying condition $(1,5)$. Its use has been demonstrated to be associated with potentially serious toxicities; particularly, renal toxicity $(7,8)$. Lipid formulations of amphotericin B were developed in an attempt to increase both efficacy and safety. The use of these agents has been approved in the event of $\mathrm{CAB}$ treatment failure due to an inadequate clinical response, the development of $\mathrm{CAB}$ intolerance or nephrotoxicity. The use of these agents has also been approved for patients with pre-existing renal disease $(6,9)$.

Although a meta-analysis of all lipid formulations in comparison with $\mathrm{CAB}$ for systemic fungal infections demonstrated a significantly reduced risk of all-cause mortality, no significant difference in treatment success rate between the lipid formulations and $\mathrm{CAB}$ was found (10). Itraconazole, an azole antifungal agent, has similar efficacy as $\mathrm{CAB}$ when administered orally (11), and guidelines recommend oral itraconazole as follow-up therapy after initial treatment with $\mathrm{CAB}$ (6). Caspofungin acetate, a specific inhibitor of fungal cell wall synthesis, is approved for the treatment of IA in patients who are refractory to or intolerant of other treatments (12). Although caspofungin acetate is generally well-tolerated and has been shown to be effective in the treatment of IA compared with a historical control group receiving standard therapy (12), its efficacy compared with CAB has not been demonstrated in randomized clinical trials.

A recent cost analysis in the US reported that the national cost burden of fungal infections is high, with an annual cost of US $\$ 2.6$ billion (13). Aspergillosis treatment was particularly costly in this study; $26 \%$ of the total cost of treating all fungal infections was spent on the $11 \%$ of patients with aspergillosis. The cost to treat one patient with IA was estimated to be US $\$ 72,792$, with hospitalization and drug costs accounting for the largest portion of the total cost.

One of the greatest impediments to the successful treatment of IA is CAB-related nephrotoxicity, which leads to increased hospital stays and is a major contributor to the cost of aspergillosis treatment (14). In one study (15), there were 212 episodes of acute renal failure among over 700 hospital admissions in which $C A B$ therapy was administered. Renal failure patients required an average of 8.2 more days in hospital and incurred an additional US $\$ 30,000$ per patient in treatment costs compared with patients who did not develop renal failure. The largest increase in resource costs were for intensive care and drugs.

A cost-effectiveness analysis of the treatment of patients with systemic mycoses who had undergone organ or bone marrow transplantation found that, in comparison with $\mathrm{CAB}$, treatment with liposomal amphotericin B (L-AMB, AmBisome, USA) was associated with fewer side effects and increased life expectancy but also substantially higher costs (16). In the study, the savings associated with fewer side effects did not offset the higher acquisition cost of the liposomal formulation.
Voriconazole, a new broad-spectrum triazole, has been shown to have potent activity against Aspergillus clinical isolates (17). The Global Comparative Aspergillosis (GCA) study, a randomized multicentre trial, compared voriconazole treatment with $\mathrm{CAB}$ treatment in 277 immunocompromised patients with definite or probable IA (18). Other licensed antifungal therapy (OLAT) were allowed if the initial therapy failed or if the patient was intolerant to the initial therapy. In the present study, OLAT included L-AMB, amphotericin B lipid complex (ABLC) and oral itraconazole. At the end of 12 weeks, $52.8 \%$ of voriconazole-treated patients exhibited complete or partial responses compared with $31.6 \%$ of CABtreated patients $(95 \%$ CI for the difference between groups of $10.4 \%$ to $32.9 \%)$. Survival was greatly improved in the voriconazole group $(70.8 \%$ versus $57.9 \%$ for $\mathrm{CAB}$; hazard ratio $0.59 ; 95 \%$ CI 0.40 to 0.88 ) and significantly fewer adverse events $(\mathrm{P}=0.02)$, including nephrotoxicity $(\mathrm{P}<0.001)$, were reported.

Although the clinical efficacy of voriconazole has been demonstrated, it remains unclear whether its use is economically advantageous in Canada. A recent economic evaluation of the costs of IA treatment in immunocompromised patients in the US (based on data from the GCA study) indicated that initiating treatment with voriconazole in comparison with $\mathrm{CAB}$ offers an average cost savings of US $\$ 3,594$ for every treated patient (19). Thus, the objective of the present study was to compare the costs and outcomes of voriconazole and $\mathrm{CAB}$ with OLAT for the treatment of definite or probable aspergillosis in Canada using a cost-consequence model based on clinical outcomes from the GCA study. The analysis was conducted from the perspective of the Canadian health care system. Since IA is predominantly treated in hospital settings, only direct costs of inpatient and outpatient hospital care were considered.

\section{Decision analytical model}

\section{METHODS}

A cost-consequence model was used to compare the cost outcomes of initiating voriconazole versus $\mathrm{CAB}$ as primary therapy for proven or probable aspergillosis. The model was based on a decision tree designed to reflect the treatment pathways relevant for clinical practice. The decision tree is presented in Figure 1 .

Treatment was initiated with either voriconazole (eg, $6 \mathrm{mg} / \mathrm{kg}$ intravenously (IV) twice a day on day 1, followed by $4 \mathrm{mg} / \mathrm{kg}$ IV twice a day for at least seven days, at which time patients could switch to oral voriconazole $200 \mathrm{mg}$ twice a day) or CAB (eg, $1.0 \mathrm{mg} / \mathrm{kg}$ to $1.5 \mathrm{mg} / \mathrm{kg}$ once a day IV). In the event of an inadequate response or severe toxicity, patients were switched from initial therapy to an OLAT. The OLAT administered during the study that were considered in the model included $\mathrm{CAB}$, L-AMB, oral itraconazole, a combination of $\mathrm{CAB}$ and oral itraconazole or a combination of $\mathrm{L}-\mathrm{AMB}$ and oral itraconazole. Similarly, patients on voriconazole could be switched to an OLAT. Switches were classified as 'early switch' or 'no early switch'. An 'early switch' was classified as a switch occurring four days or fewer after the initiation of treatment and was primarily due to infusion-related toxicity. Within the 'no early switch' group, there were five further classifications: no switch, no-response switch, renal toxicity switch, hepatotoxicity switch and switch due to other reasons (Figure 1). Progressing from IV CAB to oral itraconazole therapy or IV voriconazole to oral voriconazole therapy was not 
considered to be a switch (eg, failure) provided the reason for the switch was only to change the patient from IV to oral therapy.

Thus, there were six alternative treatment pathways in the voriconazole and CAB treatment arms (Figure 1). The number of patients expected to follow each treatment pathway is indicated in Figure 1.

For each of the treatment pathways in the model, there were two possible outcomes at the end of the 12 weeks: success or failure (Figure 1). Based on the GCA study, the cost-consequence model in the present study used two measures of success: treatment success and patient survival at week 12. Treatment success was defined as the complete or partial resolution of signs and symptoms of aspergillosis, and the requirement of patient survival at 12 weeks. Thus, patients that experienced treatment success constituted a subgroup of the patients that survived to 12 weeks.

\section{Model inputs}

Clinical outcomes and resource use: The GCA study (18), a randomized trial of 277 patients with definite or probable aspergillosis, was the main source of data for the model. The study protocol was developed under the aegis of an international steering committee that included the Invasive Fungal Infections Group of the European Organisation for Research and Treatment of Cancer to ensure that the management of aspergillosis during the study reflected current clinical practice. The primary objective of the GCA study was to demonstrate the noninferiority of voriconazole at week 12 in a modified intent-to-treat population as assessed by an independent and blinded data review committee. This population was defined as having received at least one dose of randomized treatment and had a definite or probable diagnosis of IA as assessed by the data review committee. Patients were allowed to switch to an OLAT in the event of an inadequate response or severe toxicity.

All patients in the trial were followed for 12 weeks, whether they continued to take their initial randomized treatment or switched to an OLAT. The reason for switch was classified according to the reason given by the investigator. Renal toxicity prompting a switch from initial study medication to an OLAT was decided by the treating physician in the GCA study. Moreover, discontinuation of the study drugs was recommended in the GCA study's protocol in cases of severe adverse renal or hepatic events, an increase in the serum creatinine level to double the baseline value or more than $265 \mu \mathrm{mol} / \mathrm{L}(3.0 \mathrm{mg} / \mathrm{dL})$ if the baseline value was higher than $133 \mu \mathrm{mol} / \mathrm{L}(1.5 \mathrm{mg} / \mathrm{dL})$, or an increase in aminotransferase levels to more than five times the upper limit of normal or 10 times the upper limit of normal if the baseline was more than two times the upper limit of normal (18). The GCA study provided the following data to populate the model: clinical success rates, morbidity and mortality data, treatment duration, OLAT use for each patient and resource use for the two treatment arms. Information was also derived from the GCA trial for days of IV and oral therapy, hospital length of stay and time spent on initial therapy before switching to an OLAT.

In the few instances where there was insufficient information in the GCA study, an independent expert panel was consulted (Canadian Voriconazole Advisory Board for the Pharmacoeconomic Model Validation, see appendix for a list of participants). Fifteen Canadian experts (12 physicians and three hospital pharmacists) with extensive experience in managing invasive fungal infections were surveyed. They were asked for resource use information regarding patients with aspergillosis who were successfully treated using monotherapy with each of the following drugs: CAB, L-AMB and oral itraconazole.

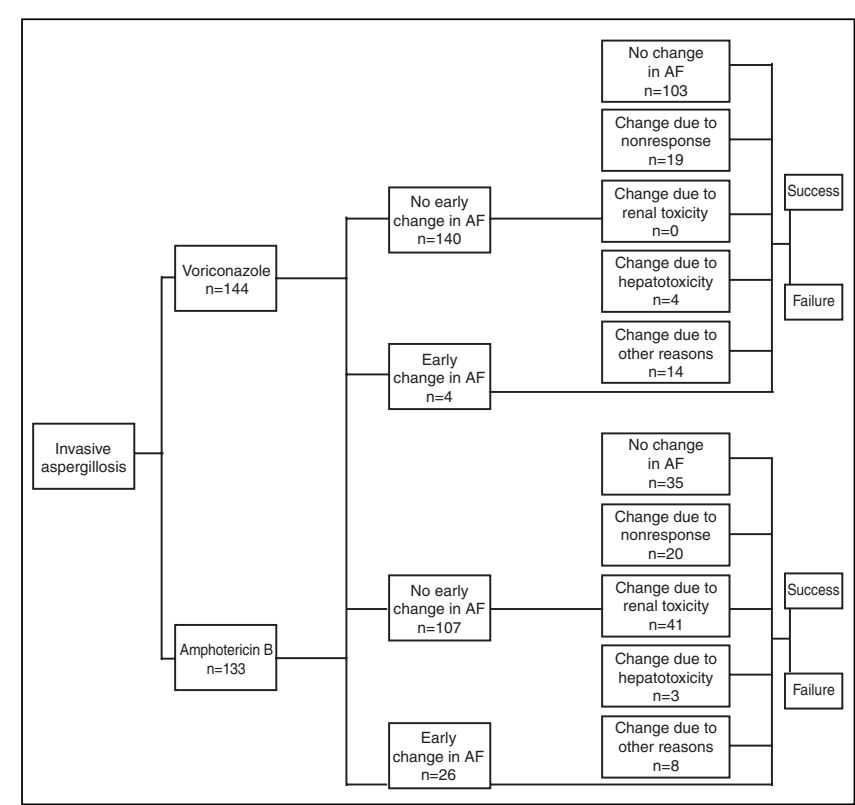

Figure 1) Decision tree for the treatment of invasive aspergillosis with voriconazole or conventional amphotericin B. Switch: switch to other licensed antifungal therapy ( $\mathrm{AF}$ ) following inadequate response or severe toxicity; Success: the complete or partial resolution of signs and symptoms of aspergillosis; Failure: inadequate response, severe toxicity or death. Numbers indicate how many patients followed each treatment pathway

The information provided by the expert panel was used to assess the duration of antifungal switch therapy with OLAT, the management of toxicities and supportive treatment. This information was also used to screen and monitor the infection. Screening data included chest x-ray, computed tomography scan, bronchoalveolar lavage and nonblood fungal cultures. Monitoring data included complete blood counts and liver and renal function tests.

Because there were differences between European and North American switch patterns in the GCA trial, the expert panel recommended using North American GCA data for the Canadian cost model. The distribution of OLAT days was determined by dividing the total number of days patients spent on each OLAT by the total number of days patients spent on all OLAT. Based on North American switch patterns, patients initially assigned to $\mathrm{CAB}$ who switched treatment ( $73.7 \%$ of all $\mathrm{CAB}$ patients) spent $45.7 \%$ of all OLAT days on L-AMB ( $n=524$ total days), $31 \%$ of all OLAT days on itraconazole ( $n=356$ total days) and $14.1 \%$ of all OLAT days on a combination of the two ( $n=62$ total days). Only $28.5 \%$ of patients initially assigned to voriconazole switched to an OLAT. Voriconazole OLAT days were primarily composed of L-AMB (64.8\%; $n=278$ total days), itraconazole $(15.4 \% ; n=66$ total days) or CAB (12.1\%; $\mathrm{n}=52$ total days).

Unit costs: All costs are reported in 2002 Canadian dollars. Costs were obtained from different Canadian provinces because costs did not vary significantly between provinces. Thus, costs were derived from different provincial sources to ensure generalizability across Canada. Further, cost information was obtained from sources that were considered by the expert panel to be the best sources of cost data. Thus, the cost of voriconazole was obtained from Pfizer Canada, the cost of $\mathrm{CAB}$ was obtained from the Ontario Drug Benefit List (20) and the cost of L-AMB was obtained from Fujisawa Canada, Inc. The cost for these agents in $\mathrm{mg} / \mathrm{kg}$ was based on a $65 \mathrm{~kg}$ patient. The expert panel recom- 
this weight assumption based on the rationale that patients at risk for IA are immunocompromised and therefore may have reduced body mass. Furthermore, the cost of itraconazole, acetaminophen, granulocyte-colony stimulating factor, diphenhydramine and meropenem were obtained from the Quebec formulary (21), while the cost of meperidine was obtained from the Saskatchewan formulary (22). In addition, the cost of hospital stays, intensive care unit (ICU) and general ward were obtained from the Cost List of Manitoba Health Services (23) All other resource costs, including outpatient visits, monitoring and screening, were obtained from the Ontario Ministry of Health and Long-Term Care Schedule of Benefits (24).

\section{Assumptions}

The model assumed a full course of treatment for those patients remaining on one of the two initial randomized treatments. The model considered a switch as a failure of initial therapy. Therefore, patients who switched were assumed to have received initial therapy up to the time they were switched. These patients were also assumed to have started therapy over with an OLAT, with all of the clinical, resource and cost sequelae associated with the new therapy. Because information on OLAT switch treatment success rates was limited, the same costs were used for all patients within a switch category. The model assessed a single episode of aspergillosis using a 12-week time horizon. Costs and outcomes were not discounted because the model duration was less than one year.

\section{Model calculations}

The cost calculations in the model were performed as follows:

1. The total cost per patient for voriconazole $\left(\mathrm{C}_{\mathrm{vor}}\right)$ and $\mathrm{CAB}$ $\left(\mathrm{C}_{\mathrm{CAB}}\right)$ treatment pathways with no switch to OLAT was calculated by adding the total costs per patient of the following: screening for fungal infections, antifungal therapy (eg, IV and step-down oral), hospitalization/care (eg, inpatient and outpatient), diagnosis/monitoring of infection, prophylaxis, monitoring and treatment of antifungal therapy side effects and treatment for neutropenic patients (eg, assumed only $40 \%$ of IA cohort).

2. The total cost per patient for voriconazole and CAB treatment pathways with a switch to an OLAT (eg, $\mathrm{C}_{\mathrm{CAB}}$ /early tox for a switch due to early toxicity; $\mathrm{C}_{\mathrm{CAB} / \text { no response }}$ for a switch due to no response; $\mathrm{C}_{\mathrm{CAB} / \text { renal tox }}$ for a switch due to renal toxicity; $\mathrm{C}_{\mathrm{CAB} / \text { hepato tox }}$ for a switch due to hepatotoxicity; $\mathrm{C}_{\mathrm{CAB}}$ /other switch for a switch due to other reasons) was calculated by adding the cost per patient of the initial voriconazole or CAB therapy to the total cost per patient of the switch therapy.

a. The cost of initial therapy with voriconazole or CAB was calculated by multiplying the average daily in-hospital cost per patient for each treatment arm (ADHC) by the number of treatment days before switching (DBS) to an OLAT in each respective switch pathway. The ADHC for voriconazole and $\mathrm{CAB}$ were calculated by dividing the total in-hospital cost per patient for each treatment arm by the average length of hospitalization. b. The total cost per patient of the OLAT therapy for each switch reason was calculated. The variables included in the calculation of the total cost per patient were mentioned previously. Because multiple consecutive changes in OLAT were observed in both the GCA study and clinical practice, the total cost per patient of each OLAT treatment (eg, COLAT-L-AMB, COLAT-Itra) was weighted according to the proportion of days spent on each OLAT in each respective switch treatment pathway (eg, $\mathrm{P}_{\mathrm{L}-\mathrm{AMB}-\mathrm{CAB} / \text { no response). }}$ ).

For example, to obtain the cost for the no response in the $\mathrm{CAB}$ arm, the following calculations were performed:

$\mathrm{C}_{\mathrm{CAB} / \text { no response }}=\left(\mathrm{ADHC}_{\mathrm{CAB}} \times \mathrm{DBS}_{\mathrm{CAB} / \text { no response }}\right)+($ COLAT-Itra $\times$ $\left.\mathrm{P}_{\text {Itra-CAB/no response }}\right)+\left(\mathrm{C}_{\text {OLAT-L-AMB }} \times \mathrm{P}_{\mathrm{L}-\mathrm{AMB}-\mathrm{CAB} / \text { no response }}\right)$ $+\left(\right.$ COLAT-L-AMB + Itra $\left.\times \mathrm{P}_{\text {L-AMB }+ \text { Itra-CAB } / \text { no response }}\right)+\ldots$ n where:

$\mathrm{P}_{\text {Itra-CAB/no response }}+\mathrm{P}_{\mathrm{L}-\mathrm{AMB}-\mathrm{CAB} / \text { no response }}+\mathrm{P}_{\mathrm{L}-\mathrm{AMB}+\mathrm{Itra}-\mathrm{CAB} / \text { no response }}$ $+\ldots=1$

3. To calculate the total average cost per patient for voriconazole and $\mathrm{CAB}$ arms, the total cost per patient with no switch $\left(\mathrm{C}_{\mathrm{CAB} / \text { no switch }}\right)$ and each switch treatment pathway $\left(\mathrm{C}_{\mathrm{CAB} / \text { early tox }}, \mathrm{C}_{\mathrm{CAB} / \text { no response, }} \mathrm{C}_{\mathrm{CAB} / \text { renal tox }}\right.$, $\mathrm{C}_{\mathrm{CAB} / \text { hepato tox }}, \mathrm{C}_{\mathrm{CAB} / \text { other switch }}$ ) weighted according to the proportion of patients in each pathway were added together.

4. The incremental cost per successfully treated case and per life saved was calculated using the difference in the average cost per patient for voriconazole and CAB arms divided by the difference in the probability of treatment success and/or survival in each respective arm.

5. The number needed to treat (NNT) in order to save one additional life was calculated based on the inverse difference in mortality between voriconazole and $\mathrm{CAB}$ treatment arms.

\section{Sensitivity analysis}

Because treatment outcomes, resource use and costs are inherently associated with a degree of variability, a sensitivity analysis was carried out in order to assess how changes in key input variables would affect the final output of the model. These variables included treatment success rates, hospital length of stay, hospital costs, treatment switches and antifungal costs. Nine different scenarios were tested:

- $\mathrm{CAB}$ total hospital length of stay for nonswitch patients was increased from 18 to 23 days (to equal the voriconazole total length of stay);

- CAB ICU bed days for nonswitch patients were increased from four to five days;

- Cost per day for a general ward bed was increased by $50 \%$;

- Cost per day for an ICU bed was decreased by 50\%;

- $\mathrm{CAB}$ time to switch was increased from 16 to 26 days (to equal the voriconazole time to switch);

- Voriconazole time to switch was decreased from 26 to 16 days (to equal the CAB time to switch); 


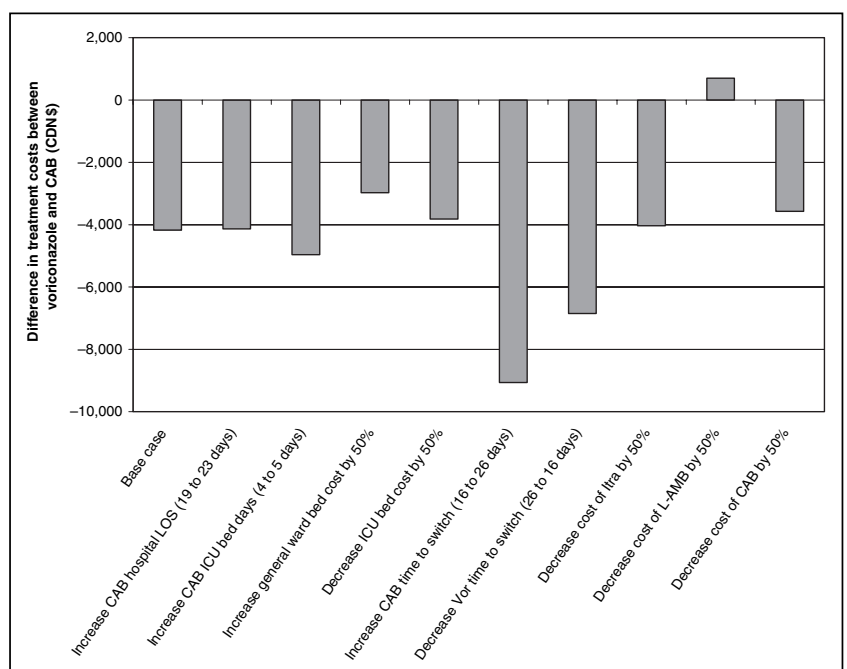

Figure 2) Difference in treatment costs between voriconazole and conventional amphotericin $B(C A B)$ : Results of the sensitivity analysis. L-AMB Liposomal amphotericin B (AmBisome, USA); Itra Itraconazole; Vor Voriconazole; LOS Length of stay; ICU Intensive care unit. Negative values indicate lower costs for voriconazole than for $\mathrm{CAB}$ treatment

- Cost of itraconazole was decreased by $50 \%$;

- Cost of L-AMB was decreased by $50 \%$;

- Cost of CAB was decreased by $50 \%$;

The results for the different scenarios are presented in Figure 2 as differences in the total average cost between voriconazole and CAB.

\section{RESULTS}

Resources used and implicated costs in Canadian dollars are listed in Table 1, while hospital lengths of stay are shown in Table 2. Hospitalization costs were $\$ 441$ per day for a general ward bed and $\$ 1,458$ per day for an ICU bed. Among patients who did not switch therapies, the mean length of hospital stay was longer for voriconazole patients than for CAB patients (23 versus 18 days, respectively) (Table 2). This observation was mainly due to the higher mortality rate of $\mathrm{CAB}$ patients $(42.1 \%$ versus $29.2 \%$ for voriconazole). However, because more CAB patients experienced toxicities and switched therapies (leading to additional days in hospital), overall, the weighted mean length of stay for each treatment arm used was almost identical (30.3 days for CAB versus 29.6 days for voriconazole).

The costs for the voriconazole and CAB treatment arms as generated by the model are presented in Table 3 . Voriconazole offered a cost savings of $\$ 4,176$ compared with CAB as the initial therapy for invasive aspergillosis (average total cost per patient of $\$ 38,319$ versus $\$ 42,495$, respectively). The weighted total cost of initiating treatment with voriconazole was influenced predominantly by patients who did not switch treatment $(71.5 \%)$, while the weighted total cost of initiating treatment with $\mathrm{CAB}$ was influenced primarily by patients who switched treatment due to major renal toxicity $(30.8 \%)$, early acute toxicity $(19.5 \%)$ and nonresponse (15\%).

Major renal toxicity was the major source of extra cost in the CAB arm. Major renal toxicity was defined based on the decision of the treating physician to stop $\mathrm{CAB}$ and prescribe
TABLE 1

Resource use and cost input to the economic model for treatment of invasive aspergillosis in Canada

\begin{tabular}{|c|c|c|}
\hline $\begin{array}{l}\mathrm{Nu} \\
\text { of ur } \\
\text { per } \\
\text { over } \\
\text { of tr }\end{array}$ & $\begin{array}{l}\text { Number } \\
\text { units used } \\
\text { er patient } \\
\text { er course } \\
\text { treatment }\end{array}$ & $\begin{array}{l}\text { Total cost per } \\
\text { patient over } \\
\text { course } \\
\text { of treatment }\end{array}$ \\
\hline \multicolumn{3}{|l|}{ Antifungal therapy } \\
\hline $\mathrm{CAB}-1 \mathrm{mg} / \mathrm{kg} /$ day IV & 21 & $\$ 1,568.70^{*}$ \\
\hline L-AMB - 5 mg/kg/day IV & 21 & $\$ 30,870.00^{*}$ \\
\hline Itra $-400 \mathrm{mg}$ oral/day (step down from IV CAB) & 7 & $\$ 186.26$ \\
\hline Itra $-400 \mathrm{mg}$ oral/day & 64 & $\$ 1,702.91$ \\
\hline Vor - 12 mg/kg/day IV & 1 & $\$ 560.00^{*}$ \\
\hline Vor - 8 mg/kg/day IV & 13 & $\$ 5,460.00^{*}$ \\
\hline Vor - $400 \mathrm{mg}$ oral/day & 50 & $\$ 4,750.00$ \\
\hline \multicolumn{3}{|l|}{$\begin{array}{l}\text { Hospitalization/outpatient care - } \\
\text { additional days due to aspergillosis }\end{array}$} \\
\hline CAB, Vor - Inpatient intensive care unit days & 4 & $\$ 5,832.00$ \\
\hline CAB - Other inpatient days & 14 & $\$ 6,174.00$ \\
\hline Vor - Other inpatient days & 19 & $\$ 8,379.00$ \\
\hline CAB - Outpatient day hospital visits & 3 & $\$ 578.76$ \\
\hline Vor - Outpatient day hospital visits & 4 & $\$ 771.68$ \\
\hline CAB, Vor - Outpatient physician visit 25 min & 2 & $\$ 224.70$ \\
\hline $\begin{array}{l}\text { L-AMB, Itra switch - Inpatient } \\
\text { intensive care unit days }\end{array}$ & 6 & $\$ 8,748.00$ \\
\hline $\begin{array}{l}\text { L-AMB, Itra switch - Outpatient physician } \\
\text { visit } 25 \text { min }\end{array}$ & 2 & $\$ 224.70$ \\
\hline L-AMB, Itra switch - Other inpatient days & 17 & $\$ 7,497.00$ \\
\hline L-AMB, Itra switch - Outpatient day hospital visits & ts 4 & $\$ 771.68$ \\
\hline \multicolumn{3}{|l|}{$\begin{array}{l}\text { Prophylaxis and treatment of } \\
\text { antifungal therapy side effects }\end{array}$} \\
\hline CAB, L-AMB - Acetaminophen 1g/day oral & 21 & $\$ 0.63$ \\
\hline CAB, L-AMB - Diphenhydramine 50 mg/day IV & 21 & $\$ 24.15$ \\
\hline CAB, L-AMB - Meperidine 50 mg/day IV & 21 & $\$ 14.49$ \\
\hline $\begin{array}{l}\text { Granulocyte colony-stimulating factor } \\
300 \mu \mathrm{g} / \text { day (neutropenic patients only }{ }^{\dagger} \text { ) }\end{array}$ & 14 & $\$ 1,380.74$ \\
\hline $\begin{array}{l}\text { Meropenem } 1.0 \text { g every } 8 \mathrm{~h} \\
\text { (neutropenic patients only }{ }^{\dagger} \text { ) }\end{array}$ & 42 & $\$ 794.30$ \\
\hline $\begin{array}{l}\text { L-AMB, Itra switch - Outpatient physician } \\
\text { visit } 25 \text { min }\end{array}$ & 2 & $\$ 224.70$ \\
\hline \multicolumn{3}{|l|}{ Diagnosis and monitoring } \\
\hline Chest x-ray & 6 & $\$ 133.50$ \\
\hline Computed tomography scan & 2 & $\$ 131.20$ \\
\hline Bronchoalveolar lavage & 1 & $\$ 134.65$ \\
\hline Fungal culture (nonblood) & 1 & $\$ 20.00$ \\
\hline \multicolumn{3}{|l|}{ Monitoring for side effects } \\
\hline Complete blood count & 6 & $\$ 96.00$ \\
\hline Renal function test & 6 & $\$ 156.00$ \\
\hline Liver function test & 6 & $\$ 30.00$ \\
\hline
\end{tabular}

${ }^{*}$ Cost based on a $65 \mathrm{~kg}$ patient. ${ }^{\dagger}$ Assumed only $40 \%$ of cohort neutropenic thus a weighted cost per patient for granulocyte colony-stimulating factor and meropenem is used in the model. All costs are listed in Canadian dollars. $C A B$ Conventional amphotericin B; Itra Itraconazole; L-AMB Liposomal amphotericin B (AmBisome, USA); Vor Voriconazole

an OLAT following signs of renal toxicity. Because switching increased the hospital length of stay, the cost of treating a patient who switched treatment due to major renal toxicity was $\$ 60,779$ compared with a cost of $\$ 17,480$ for a patient who remained on $\mathrm{CAB}$ treatment. In comparison, switches due to 
TABLE 2

Hospital lengths of stay: Input to the economic model for the treatment of invasive aspergillosis in Canada

\begin{tabular}{lccc}
\hline & \multicolumn{2}{c}{ Hospital length of stay for patients } \\
& $\begin{array}{c}\text { Treated } \\
\text { with CAB }\end{array}$ & $\begin{array}{c}\text { Treated with } \\
\text { voriconazole }\end{array}$ & $\begin{array}{c}\text { Switched } \\
\text { to OLAT }\end{array}$ \\
\hline ICU bed days & 4 & 4 & +6 \\
Other inpatient bed days & 14 & 19 & +17 \\
Total of all inpatient bed days & 18 & 23 & +23 \\
Day hospital/home infusion & 3 & 4 & +4 \\
\hline
\end{tabular}

+ Indicates the number of days in addition to the days on initial therapy with voriconazole or conventional amphotericin B (CAB); OLAT Other licensed antifungal therapy; ICU Intensive care unit

renal toxicity were absent in the voriconazole arm and, therefore, no extra costs were incurred.

Cost-effectiveness analyses demonstrated that voriconazole was both more effective and less costly than CAB. Indeed, the probabilities of a successful treatment outcome and survival were higher for voriconazole. The total cost per treatment success and the total cost per survivor were lower for patients treated with voriconazole than for those treated with CAB. The incremental costs per successfully treated case and per life saved with voriconazole were negative. Thus, voriconazole dominated $\mathrm{CAB}$ as a treatment option (Table 4).

The absolute reduction in mortality risk for the voriconazole arm over the CAB arm was $12.9 \%$ (Table 4 ), and the NNT, which is the reciprocal of the absolute risk reduction, was 8 (25). Thus, treating eight patients with voriconazole instead of CAB would save one additional life.

\section{Sensitivity analysis}

The nine scenarios tested in the sensitivity analysis demonstrated that the dominance of voriconazole over CAB was robust (Figure 2). In the base case, voriconazole use resulted in cost savings of $\$ 4,176$ per patient when compared with CAB. The model was sensitive to changes in hospital costs: a $50 \%$ increase in the cost per day of a general ward bed resulted in cost savings of $\$ 2,973$ for voriconazole, and a $50 \%$ decrease in ICU bed cost led to cost savings of $\$ 3,817$ for voriconazole. The model was also sensitive to the time to switch: increasing the CAB time to switch and decreasing the voriconazole time to switch improved the cost savings for voriconazole to $\$ 9,068$ and $\$ 6,853$, respectively. A $50 \%$ reduction in the cost of $\mathrm{L}$-AMB was the only scenario in which voriconazole no longer saved costs. However, in this scenario, the cost associated with voriconazole was only $\$ 698$ greater than with CAB (Figure 2).

\section{DISCUSSION}

Poor clinical outcomes and increased resource use can negate the anticipated cost savings of a drug with a low acquisition price, while improved clinical outcomes and reduced resource use can offset cost increases related to higher acquisition costs. Therefore, comparisons of the relative costs of antifungal agents should be predicated on total associated costs, including the cost of hospital stay, cost of treating drug-related adverse events, the cost switching or adding therapies and drug acquisition costs. The reasons for switching from the initial therapy (eg, voriconazole or CAB) included a switch due to an infusion-related toxicity, lack of response (eg, efficacy), renal toxicity, hepatotoxicity and other reasons (26).

CAB has traditionally been used because of its broadspectrum activity, clinical efficacy and low acquisition cost. However, the total cost of treatment with this antifungal is greatly increased by the costs involved in preventing and treating adverse events (27) (particularly renal toxicity [15]), and the necessity to switch patients to an OLAT because of toxicity or lack of efficacy (8). In the present study, almost $31 \%$ of CAB-treated patients switched to another antifungal, mainly due to renal toxicity at an incremental cost of $\$ 42,495$ per patient. Similarly, in a US study (15), the incremental cost for patients experiencing CAB-related nephrotoxicity reported in $30 \%$ of cases was US $\$ 30,000$ per patient.

The incidence of renal- and infusion-related toxicity is generally lower with L-AMB or ABLC than with CAB (12). An economic analysis of empirical antifungal therapy in persistently febrile neutropenic patients investigated to what degree savings associated with reduced nephrotoxicity could offset higher acquisition costs of the liposomal formulation (28). Despite a lower incidence of nephrotoxicity in the L-AMB group (19\% for L-AMB versus 34\% for CAB), overall hospital costs were significantly higher with L-AMB than with CAB (US $\$ 48,962$ versus US $\$ 43,183$, respectively). This was due to the substantially higher drug acquisition costs associated with L-AMB (US\$188.40 for L-AMB versus US $\$ 16.60$ for CAB per $50 \mathrm{mg}$ vial). Only at an acquisition cost of US\$72.00 would L-AMB become less costly than CAB. Although these findings cannot be directly applied to the treatment of confirmed or suspected IA, they suggest that L-AMB may not be economically attractive as first-line therapy in this indication.

In addition, a recent pharmacoeconomic impact model of voriconazole versus L-AMB in the treatment of systemic fungal infections in immunocompromised patients projected that modest shifts in prescription patterns from L-AMB to voriconazole could lead to annual savings in antifungal drug

TABLE 3

Total cost of voriconazole and conventional amphotericin B deoxycholate treatment for aspergillosis

\begin{tabular}{|c|c|c|c|c|c|c|}
\hline \multirow[b]{2}{*}{ Treatment switches } & \multicolumn{3}{|c|}{ Amphotericin B deoxycholate } & \multicolumn{3}{|c|}{ Voriconazole } \\
\hline & Weight ${ }^{\star \dagger}$ & $\operatorname{Cost}^{\dagger}$ & Weighted cost & Weight $^{* \dagger}$ & $\operatorname{Cost}^{\dagger}$ & Weighted cost \\
\hline None $^{\ddagger}$ & $0.263^{\ddagger}$ & 17,480 & 4,600 & 0.715 & 28,853 & 20,638 \\
\hline Nonresponse & 0.150 & 50,590 & 7,607 & 0.132 & 64,561 & 8,518 \\
\hline Major renal toxicity & 0.308 & 60,779 & 18,736 & 0.000 & 0 & 0 \\
\hline Major hepatotoxicity & 0.023 & 40,696 & 917 & 0.028 & 49,875 & 1,385 \\
\hline Average total cost per patient & & & 42,495 & & & 38,319 \\
\hline
\end{tabular}

*Weights are derived from the GCA study (18). ${ }^{\dagger}$ All figures have been rounded, so manual calculations may appear imprecise (eg, 0.263 has been rounded from 0.26315789). IIncludes intravenous conventional amphotericin B with step down oral itraconazole. All costs are listed in Canadian dollars. 
costs in the range of US\$20,846 to US\$62,537 for an institutionalized population of 100 patients (29). The projected savings were attributable to lower wholesale acquisition costs of voriconazole compared with L-AMB and the availability of an oral formulation of voriconazole.

The average cost saving of $\$ 4,176$ per patient in the present study compares well with an estimated cost saving of $\$ 6,000$ (approximately US\$3,594) in another study (19) comparing treatment costs of voriconazole versus $\mathrm{CAB}$ in the US based on outcomes of the GCA study. As in the present analysis, the US study found that the main cost drivers in the CAB treatment arm were costs associated with switches to an OLAT due to renal toxicity and early toxicity (19). A substantial part of these additional costs stemmed from the high acquisition costs of the L-AMB (19). Another economic analysis based on outcomes of the GCA trial evaluated the cost of antifungal medication for patients randomized to voriconazole and CAB followed by an OLAT treatment (30). Overall drug costs per patient in this analysis were US\$772 lower for patients randomized to initial treatment with voriconazole compared with $\mathrm{CAB}$. This was due to the higher proportion of patients in the CAB arm switching to an OLAT treatment (80\% versus 36\% in the voriconazole arm) and the relatively high cost of OLAT drugs (30). The economic advantage of voriconazole was made more obvious when total antifungal drug costs per successfully treated patient were compared (US\$10,305 for the voriconazole arm versus US $\$ 19,667$ for the CAB arm) (30).

According to the cost-consequence model used in the present study, the use of voriconazole as primary therapy for IA instead of the current gold standard (CAB, followed by any other approved antifungal therapy) would generate substantial economic benefits in Canada. Treatment with voriconazole resulted in an average cost savings of $\$ 4,176$ per patient relative to CAB. The cost per successfully treated patient was $\$ 72,604$ and $\$ 134,569$ for voriconazole and CAB, respectively, while the cost per life saved was $\$ 54,123$ and $\$ 73,395$ for voriconazole and $\mathrm{CAB}$, respectively. Moreover, success and survival rates were significantly higher when treatment was initiated with voriconazole. The markedly higher survival rate in voriconazole-treated patients yielded a NNT value of eight for treatment with voriconazole compared with usual therapy with CAB. The NNT value of eight indicates that if eight patients are treated with voriconazole instead of $\mathrm{CAB}$, one additional death will be averted within a 12-week timeframe. For comparison, a recent meta-analysis of the antifungal effectiveness and tolerability of amphotericin B formulations in the treatment of systemic fungal infections estimated that, overall, 31 patients need to be treated with lipid formulations of amphotericin $\mathrm{B}$ instead of $\mathrm{CAB}$ in order to prevent one death (10).

There are some limitations to the present study. First, the structure of the decision tree model described in the analysis assumes a simplified switch pattern. Although the model appropriately reflects treatment patterns and health resource use data from the clinical trial, it is a simplification of current medical practice. In addition, based on GCA study data, the average duration of antifungal therapy was lower for $\mathrm{CAB}$ patients than voriconazole patients because patients in the $\mathrm{CAB}$ arm died sooner. This tended to bias the results against voriconazole.

Second, model resource use was not broken down by success and failure of each type of switch because the numbers were

\section{TABLE 4}

Canadian economic model of voriconazole for invasive aspergillosis treatment: Base case results

\begin{tabular}{|c|c|c|c|}
\hline Results & CAB & Voriconazole & $\begin{array}{c}\text { Difference } \\
\text { (Vor - CAB) }\end{array}$ \\
\hline Probability of success without switch & 0.053 & 0.403 & +0.350 \\
\hline $\begin{array}{l}\text { Probability of successful treatment } \\
\text { (including switches) }\end{array}$ & 0.309 & 0.521 & +0.212 \\
\hline Probability of survival & 0.579 & 0.708 & +0.129 \\
\hline Total average cost per patient & $\$ 42,495$ & $\$ 38,319$ & $-\$ 4,176$ \\
\hline Cost per successfully treated patient & $\$ 134,569$ & $\$ 72,604$ & \\
\hline Cost per survivor & $\$ 73,395$ & $\$ 54,123$ & \\
\hline $\begin{array}{l}\text { Incremental cost per successfully } \\
\text { treated patient }\end{array}$ & & Dominant & $<\$ 0$ \\
\hline Incremental cost per life saved & & Dominant & $<\$ 0$ \\
\hline
\end{tabular}

CAB Conventional amphotericin B; Vor Voriconazole

too small. Large variability between these small numbers could have distorted the results. To minimize potential distortions, outcomes were aggregated at a success versus failure level for all patients in each treatment group, and costs were aggregated for each type of switch by treatment group.

Third, in order to simplify our model, we assumed that L-AMB was the sole lipid formulation of amphotericin B employed as an OLAT. In fact, in the GCA study, L-AMB was used as an OLAT two-thirds of the time, while ABLC was administered one-third of the time. The use of ABLC as an alternative to $\mathrm{L}$-AMB was not considered in the economic evaluation. While ABLC is less expensive than L-AMB, it may be somewhat less efficacious for the treatment of IA (31). However, this issue was addressed in the sensitivity analysis when a $50 \%$ reduction in the cost of L-AMB (eg, a cost comparable to that of ABLC) was considered. The sensitivity analysis for a $50 \%$ reduction in the cost of L-AMB demonstrated that voriconazole remained almost cost-neutral when compared with CAB therapy followed by an OLAT, indicating that there is a wide margin within which the ratio of cost-toconsequence of using voriconazole remains favourable. Therefore, even if ABLC and L-AMB were used one-third and two-thirds of the time, respectively, it would have had little impact on the outcome of the model, which favoured voriconazole.

Fourth, caspofungin acetate was not considered as one of the OLAT antifungals because it was not available at the time of the GCA study. Further, there are no studies comparing the efficacy and safety of voriconazole with that of caspofungin acetate in the treatment of IA. Finally, the model assumed a switch from IV voriconazole to the oral formulation by day 15 of therapy. The duration of IV voriconazole was recommended by the expert panel of advisors based on the anticipated duration of IV therapy reflective of clinical practice in Canada. This recommendation was in keeping with the mean duration of IV voriconazole in the GCA study (15 days, Pfizer internal document, unpublished data) for patients receiving a full course of voriconazole therapy. The median duration of IV voriconazole therapy (10 days) reported by Herbrecht et al (18) included both patients receiving a full course of voriconazole therapy and switching to an OLAT. Should the therapeutic sequence be altered by increasing the duration of IV voriconazole therapy, the voriconazole drug acquisition costs would certainly be inflated, thus reducing any potential cost reductions 
associated with its use. However, it is unlikely that the mean length of IV voriconazole would extend beyond 14 days. In contrast, a reduction in the duration of IV voriconazole therapy would simultaneously reduce drug costs.

In summary, the cost-consequence model for IA suggests that a voriconazole treatment regimen is both more clinically and cost effective in Canada than CAB treatment. Substantial economic benefits may arise from the use of voriconazole as primary therapy for IA. These benefits would be achieved despite the choice of best available therapy (CAB followed by other approved antifungal therapies, including L-AMB, ABLC and oral itraconazole). Voriconazole increases the chances of successfully treating IA, improves patient survival and may potentially save costs in Canada.

APPENDIX: The following individuals were members of the Canadian Voriconazole Advisory Board for the Pharmacoeconomic Model Validation who participated in the meeting held in Ottawa, September 5, 2002: Dr Upton Allen, The Hospital for Sick Children, Toronto, Ontario; Dr Eric Bow, Health Sciences Centre, Winnipeg, Manitoba; Ms Sylvie Carle, Royal Victoria Hospital, Montreal, Quebec; Dr Ronald Feld, Princess Margaret Hospital, Toronto, Ontario; Dr Gary Garber, Ottawa General Hospital, Ottawa, Ontario; Dr Alfred Gin, Health Sciences Centre, Winnipeg, Manitoba; Dr David Haase, Queen Elizabeth II Health Sciences Centre, Halifax, Nova Scotia; Dr Atul Humar, Toronto General Hospital, Toronto, Ontario; Dr Michel Laverdiere, Hopital Maisonneuve-Rosemont, Montreal, Quebec; Dr Rene Pelletier, Hopital Hotel Dieu de Quebec, Quebec City, Quebec; Dr Peter Phillips, Vancouver General Hospital and St Paul's Hospital, Vancouver, British Columbia; Dr Coleman Rotstein, Hamilton Health Sciences, Hamilton, Ontario; Dr Stephen Sanche, Royal University Hospital, Saskatoon, Saskatchewan; Dr Stephen Shafran, University of Alberta Hospital, Edmonton, Alberta; and Mr Gary Wong, Toronto General Hospital, Toronto, Ontario.

ACKNOWLEDGEMENTS: The authors wish to thank investigators and significant contributors; particularly, Micheal Ortiz, RTI Health Solutions. This study was made possible by a grant from Pfizer Canada Inc. BioMedCom Consultants Inc, Montreal, Canada, assisted in the presentation of the data.

\section{REFERENCES}

1. Denning DW. Invasive aspergillosis. Clin Infect Dis 1998;26:781-803.

2. Beck-Sague C, Jarvis WR. Secular trends in the epidemiology of nosocomial fungal infections in the United States, 1980-1990. National Nosocomial Infections Surveillance System. J Infect Dis 1993; 167:1247-51.

3. Chandrasekar PH, Cutright JL, Manavathu EK. Aspergillus: Rising frequency of clinical isolation and continued susceptibility to antifungal agents, 1994-1999. Diagn Microbiol Infect Dis 2001;41:211-4.

4. Nicolle L, Rotstein C, Bourgault A, St-Germain G, Garber G. Invasive fungal infections in Canada from 1992 to 1994. Can J Infect Dis 1998;9:347-52.

5. Denning DW. Therapeutic outcome in invasive aspergillosis. Clin Infect Dis 1996;23:608-15

6. Stevens DA, Kan VL, Judson MA, et al. Practice guidelines for diseases caused by Aspergillus. Infectious Diseases Society of America. Clin Infect Dis 2000;30:696-709.

7. Harbarth S, Pestotnik SL, Lloyd JF, Burke JP, Samore MH. The epidemiology of nephrotoxicity associated with conventional amphotericin B therapy. Am J Med 2001;111:528-34.

8. Wingard JR, Kubilis P, Lee L, et al. Clinical significance of nephrotoxicity in patients treated with amphotericin B for suspected or proven aspergillosis. Clin Infect Dis 1999;29:1402-7.
9. Harari S. Current strategies in the treatment of invasive Aspergillus infections in immunocompromised patients. Drugs 1999;58:621-31.

10. Barrett JP, Vardulaki KA, Conlon C, et al. A systematic review of the antifungal effectiveness and tolerability of amphotericin $\mathrm{B}$ formulations. Clin Ther 2003;25:1295-320.

11. Denning DW, Lee JY, Hostetler JS, et al. NIAID Mycoses Study Group Multicenter Trial of Oral Itraconazole Therapy for Invasive Aspergillosis. Am J Med 1994;97:135-44.

12. Polak A. Antifungal therapy - State of the art at the beginning of the 21st century. Prog Drug Res 2003;Spec No:59-190.

13. Wilson LS, Reyes CM, Stolpman M, Speckman J, Allen K, Beney J. The direct cost and incidence of systemic fungal infections. Value Health 2002;5:26-34.

14. van Gool R. The cost of treating systemic fungal infections. Drugs 2001;61(Suppl 1):49-56.

15. Bates DW, Su L, Yu DT, et al. Mortality and costs of acute renal failure associated with amphotericin B therapy. Clin Infect Dis 2001;32:686-93.

16. Persson U, Tennvall GR, Andersson S, Tyden G, Wettermark B. Cost-effectiveness analysis of treatment with liposomal amphotericin B versus conventional amphotericin B in organ or bone marrow transplant recipients with systemic mycoses. Pharmacoeconomics 1992;2:500-8.

17. Murphy M, Bernard EM, Ishimaru T, Armstrong D. Activity of voriconazole (UK-109,496) against clinical isolates of Aspergillus species and its effectiveness in an experimental model of invasive pulmonary aspergillosis. Antimicrob Agents Chemother 1997;41:696-8.

18. Herbrecht R, Denning DW, Patterson TF, et al. Voriconazole versus amphotericin B for primary therapy of invasive aspergillosis. N Engl J Med 2002;347:408-15.

19. Marciniak A, Mauskopf J, Wenzel R, et al. Cost-consequence model for comparing voriconazole with conventional amphotericin $\mathrm{B}$ as initial antifungal therapy in the treatment of invasive aspergillosis. Poster presented at the International Health Economic Association. San Francisco, June 15 to 18, 2003.

20. Ontario Drug Benefit Formulary/Comparative Index (No. 37 and updates). Ontario Ministry of Health and Long-Term Care, Ontario, 2002.

21. Liste de medicaments Quebec. 2002. Regie de l'Assurance Maladie du Quebec.

22. Saskatchewan Health Drug Plan Formulary (51st edition and updates). Pharmaceutical Services Division, Drug Plan and Extended Benefits Branch, Saskatchewan Health, Saskatchewan, 2002.

23. Jacobs P, Shanahan M, Roos NP, Farnworth M. Cost for Manitoba Health Services. Manitoba Centre for Health Policy and Evaluation. January 1999.

24. Ministry of Health and Long-Term Care: Schedule of Benefits, Physician Services under the Health Insurance Act. Government of Ontario, April 1, 2002.

25. Walter SD. Number needed to treat (NNT): Estimation of a measure of clinical benefit. Stat Med 2001;20:3947-62.

26. Cordell WH. Number needed to treat (NNT). Ann Emerg Med 1999;33:433-6

27. Rex JH, Walsh TJ. Estimating the true cost of amphotericin B. Clin Infect Dis 1999;29:1408-10.

28. Cagnoni PJ, Walsh TJ, Prendergast MM, et al. Pharmacoeconomic analysis of liposomal amphotericin $B$ versus conventional amphotericin B in the empirical treatment of persistently febrile neutropenic patients. J Clin Oncol 2000;18:2476-83.

29. Lloyd MD, Faulkner ST. A pharmacoeconomic impact analysis of voriconazole therapy versus liposomal amphotericin B therapy. Poster presented at the Summer Meeting of the American Society of Health-System Pharmacists (ASHP), San Diego, May 31 to June 4, 2003.

30. Lewis JS, Boucher HW, Lubowski T, Ambegaonkar AJ, Day D, Patterson TF. Economic advantage of voriconazole (VRC) for primary treatment of invasive aspergillosis compared to conventional amphotericin B (CAB). 43rd Interscience Conference on Antimicrobial Agents and Chemotherapy, American Society for Microbiology. Chicago, September 14 to 17, 2003.

31. Walsh TJ, Hiemenz JW, Seibel NL, et al. Amphotericin B lipid complex for invasive fungal infections: Analysis of safety and efficacy in 556 cases. Clin Infect Dis 1998;26:1383-96. 


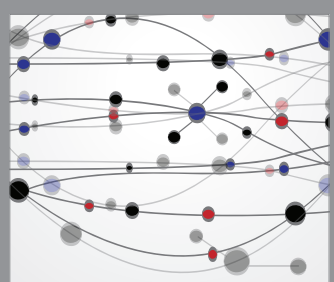

The Scientific World Journal
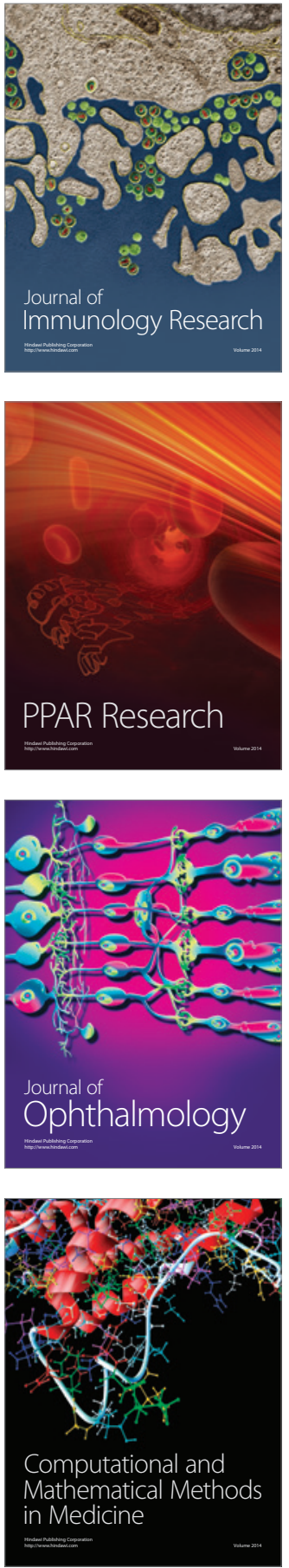

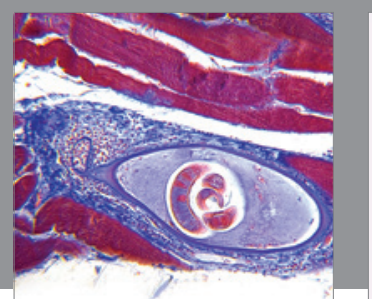

Gastroenterology Research and Practice

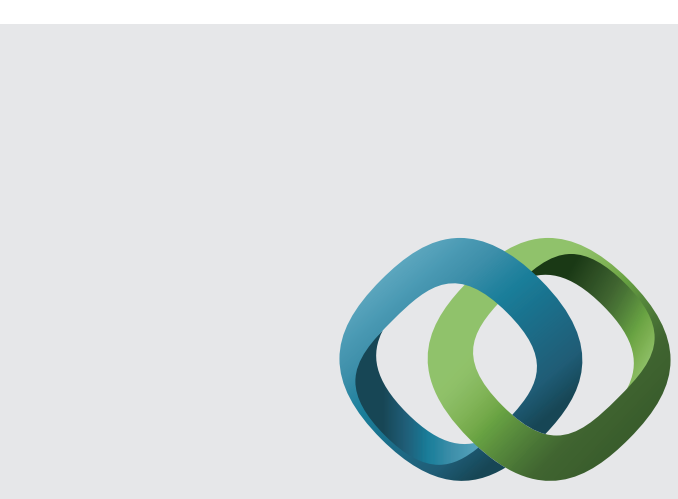

\section{Hindawi}

Submit your manuscripts at

http://www.hindawi.com
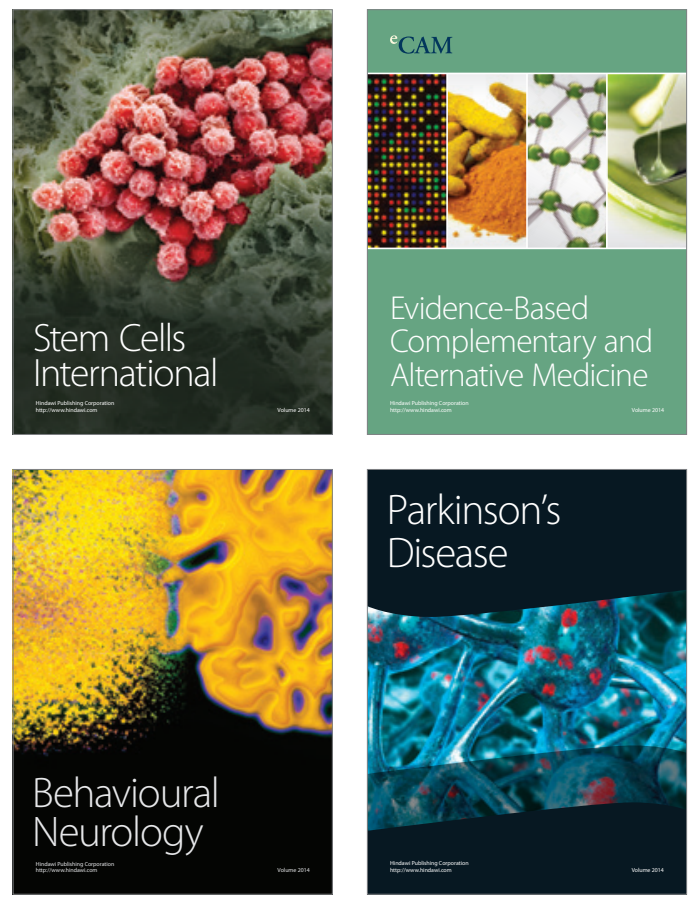
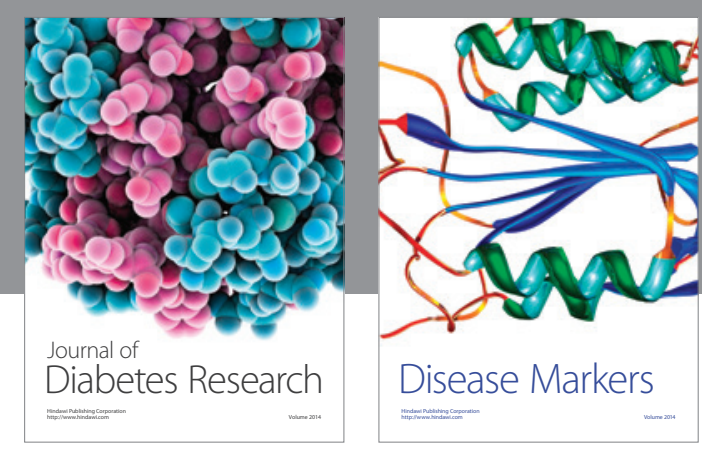

Disease Markers
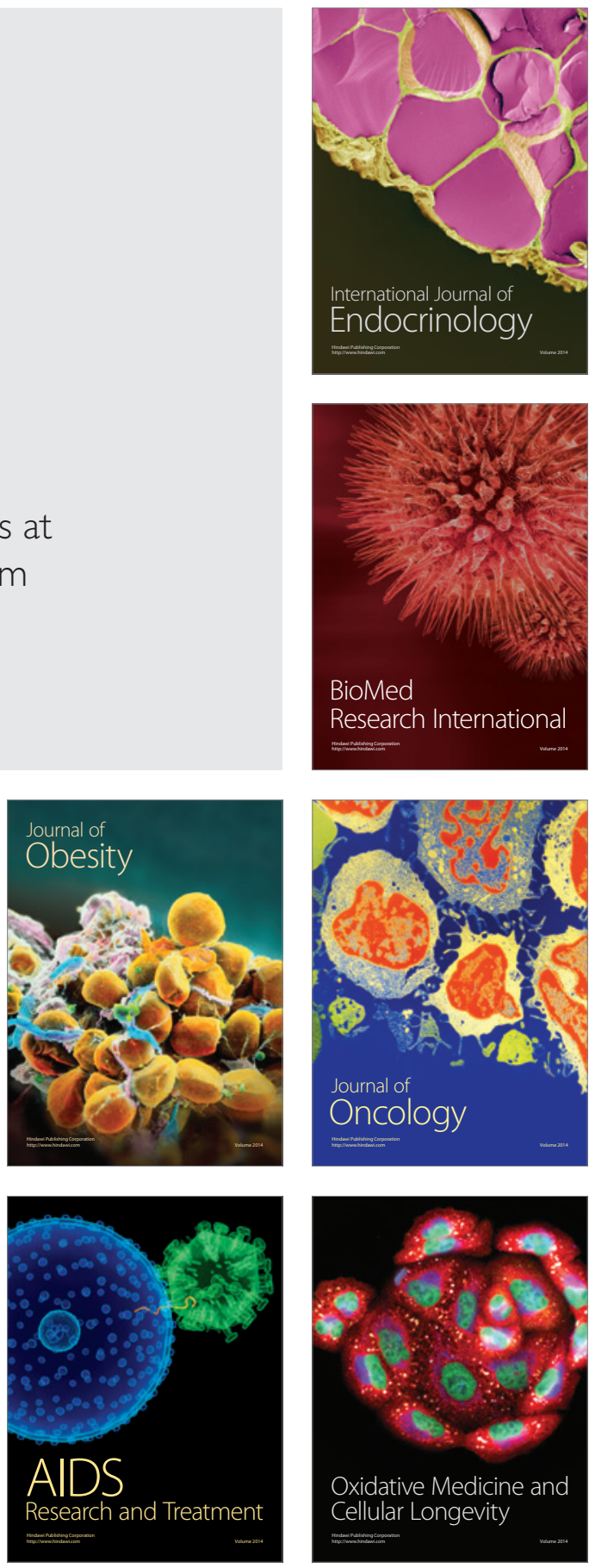